\title{
Abordagens teóricas de tratamento temático da informação (TTI): catalogação de assunto, indexação e análise documental (1)
}

Theoretical approaches on information subject treatment: subject cataloging, indexing and subject analysis

\author{
José Augusto Chaves GuIMARÃES \\ Universidade Estadual Paulista - Marília-SP - Brasil. E-mail: guima@marilia.unesp.br
}

\begin{abstract}
Resumo:
Considerando el espacio conceptual ocupado por el tratamiento temático de la información en el ámbito de la enseñaza y de la investigación en Biblioteconomía, se discute la catalogación temática, la indización y el análisis documental en cuanto que corrientes teóricas que históricamente han contribuido a la construcción del universo epistemológico de esta área de estudios. Por tanto, con base en la literatura internacional, se analizan los aspectos conceptuales de cada una de esas corrientes para identificar sus trazos distintivos y sus puntos de convergencia y complementariedad.
\end{abstract}

Palabras clave: Tratamento temático de la información. Análisis documental. Catalogación temática. Indización.

\section{Tratamento temático da informação: elementos históricos e conceituais}

A Ciência da Informação, campo científico interdisciplinar cujos pressupostos teóricometodológicos fornecem base conceitual para distintos fazeres profissionais, como a Biblioteconomia (Pinheiro, 1999; Smit \& Barreto, 2002) encontra, na produção, na organização e no uso da informação, enquanto etapas do ciclo de operações documentárias (Kobashi, 1994), a base sobre a qual se assenta seu universo epistemológico.

Especificamente no âmbito da organização da informação, atividade de natureza eminentemente mediadora, dois universos de descortinam: o primeiro, ligado ao acesso físico aos documentos e o segundo, de natureza mais complexa, voltado para o acesso ao conteúdo informacional, genericamente denominado de Tratamento Temático da Informação - T.T.I. (Foskett, 1973) ou, como prefere Ruiz Perez (1992), análise documental de forma e de conteúdo. Pode-se dizer, assim, que a distinção entre tais abordagens reside na busca do o que

\begin{abstract}
:
Considering the core position occupied by Information Subject Treatment in the LIS field, it carries out a discussion on subject cataloguing, indexing as well as subject analysis while theoretical approaches which have been historically contributing to the epistemological universe of such branch. In this sense and basing on the international LIS literature, it discusses the conceptual aspects of each mentioned theoretical approach in order to identify their distinctive traces as well as convergent and / or complementary points among them.
\end{abstract}

Keywords: Indexing. Subject analysis. Subject cataloguing.

(materialização) e do sobre o que (teor) que convivem no âmbito do documento.

Desse modo, observa-se que um conhecimento registrado (informação socializada) requer que sobre ele se desenvolvam processos específicos de organização que propiciem sua passagem da dimensão pública para a dimensão privada, ou seja, a construção do conhecimento individual (Guimarães, 2001) que, por sua vez gerará uma nova informação registrada para ser socializada, caracterizando um verdadeiro helicóide informacional (2).

Nesse âmbito, Barité (2001, p. 42-53), ao justificar o processo de organização do conhecimento $e$, por conseguinte, da informação, enquanto núcleo duro da Ciência da Informação destaca que o conhecimento é um produto, uma necessidade e um dínamo social que se realiza a partir da informação e, ao socializar-se, se transforma em informação. Desse modo, pode ser organizado de $n$ formas (todas elas artificiais, provisórias e deterministas) para seu melhor aproveitamento social e individual. Esse conhecimento, por sua vez, materializa-se em docu- 
mentos e se expressa por meio de conceitos organizados em sistemas de conceitos que se prestam a fins científicos, literários, funcionais ou de documentação.

Observa-se, destarte, que a organização da informação deve ser entendida como um conjunto de procedimentos que incidem sobre um conhecimento socializado (que, por sua vez, é um produto social e tem uma utilidade social e individual), os quais variam em virtude dos contextos em que são produzidos ou os fins a que se destinam, pois é a partir destes que se desenvolvem os parâmetros de organização.

Nesse contexto, a questão dos conteúdos informacionais emerge como um ponto fundamental a ser abordado, assumindo papel estratégico em arquivos, bibliotecas e museus, enquanto instituições coletoras de cultura (Homulos, 1990). Isso ocorre em virtude de sua capacidade de agregar valor ao conhecimento, "notadamente em termos de conteúdo uma vez que o documento, enquanto registro de conhecimento, passa a ser o de representante ou substituto de idéias e criações", refletindo aquilo que Cubillo (1999, p. 17), denomina surrogate of knowledge, ou seja, um substituto do conhecimento gerado por alguém que normalmente não pode estar presente (Guimarães, 2002).

Indo além, Vieira (1998, p. 86), ao se referir a mudanças e condicionantes para a inserção efetiva de países em desenvolvimento em um contexto de sociedade da informação, destaca a organização da informação como fundamental para que efetivamente ocorra "disponibilização de conteúdos informacionais", tornando-se necessários, para tanto, "rígidos critérios de qualidade técnica e observação de padrões e normas internacionais que permitam sua utilização pelo usuário final".

Em termos históricos, o T.T.I. teve seu desenvolvimento norteado por duas influências que se complementaram: por um lado, e em uma vertente teórica, tem-se as concepções filosóficas de Platão, Aristóteles e Bacon, dentre outros, relativamente à divisão do conhecimento e, por outro, em uma vertente mais pragmática, norteada pela necessidade prática de organização documental - o que, em última análise, reflete aquilo que Smit, (1986, p. 12) define como "reunir e organizar para achar" -, resultando nas denominadas classificações bibliográficas (San Segundo, 1996) (3).

Em termos mais amplos, pode-se dizer que o T.T.I. centra-se nas questões atinentes "à análise, descrição e representação do conteúdo dos documentos, bem como suas inevitáveis interfaces com as teorias e sistemas de armazena- mento e recuperação da informação" (Barité, 1997, p. 124) em cujo âmbito desenvolvem-se processos, valendo-se de instrumentos para a geração de produtos.

Esse universo, por sua vez, apresenta-se, na literatura especializada, sob três vertentes teóricas, nomeadamente: a catalogação de assunto (subject cataloguing) de matriz norte-americana, a indexação (indexing) de matriz inglesa e a análise documental (analyse documentaire), de matriz francesa, como se verá a seguir.

\section{Catalogação de assunto}

Essa abordagem teórica, historicamente anterior às demais, na medida em que remonta à segunda metade do século XIX, apresenta nítida matriz norte-americana, em muito norteada pelos princípios de catalogação alfabética de Cutter e da tradição de cabeçalhos de assunto da Library of Congress, cuja ênfase reside no catálogo enquanto produto do tratamento da informação em bibliotecas (subject cataloguing).

Enquanto "representação, nos catálogos de biblioteca, dos assuntos contidos no acervo" (Fiuza, 1985, p. 257) a catalogação de assunto encontrou significativo substrato, também, nos trabalhos históricos de Kaiser e Coates e, na atualidade, de autores Hope Olson e Sanford Berman, dentre outros.

Refletindo uma tradição anglo-saxônica de preocupação mais pragmática, centrada primordialmente nos produtos a serem gerados no T.T.I., o conceito de catalogação, assume uma dimensão mais abrangente, representando todo o processo de tratamento da informação.

Nessa linha de abordagem, Raju \& Raju (2006, p. 12) concebem a catalogação enquanto "processo de preparação de entradas para um catálogo, com base em um conjunto de regras, de tal forma a permitir ao usuário o conhecimento dos documentos disponíveis e de sua respectiva localização". Indo ao encontro de tal concepção, Sanchez Luna (2004, p. 83) refere-se a uma "operação pela qual se identifica o documento em função de suas características formais e de seu conteúdo, tais como o autor, o título, o local de publicação, o editor, o ano de publicação assim como o tema da obra". Para tanto, a autora aborda a catalogação como um grande universo de tratamento documental em cujo âmbito se inserem a catalogação descritiva, a catalogação de assunto e, ainda, a classificação, como universo notacional de localização física do documento em bibliotecas organizadas pelo arranjo sistemático. 
Assim, entendida como universo de tratamento documental, a catalogação, nessa concepção teórica, igualmente revela as dimensões de forma e de conteúdo, por meio das denominadas catalogação descritiva e catalogação de assunto. Nesse sentido, sintetiza Sanchez Luna (2204, p. 83) que a catalogação atua como um "processo sujeito a normas estritas" com o objetivo de "preparar informação bibliográfica para criar registros bibliográficos".

Mas é especificamente na catalogação de assunto que se encontra a dimensão do T.T.I. Autores como Coates (1988, p. 10), em uma abordagem mais pragmática, a ela se referem a partir de sua função - "dirige o usuário de palavras-chave para documentos" - O referido autor destaca que "os catálogos de assunto têm uma dupla função: possibilitar ao usuário identificar documentos sobre um determinado assunto bem como sobre assuntos correlatos" (Coates, 1988, p. 19).

Por outro lado, autores outros, como Raju \& Raju (2006, p. 15), destacam o fato de nela se desenvolver a denominada "análise de assunto" que gerará a representação do conteúdo dos documentos por meio de notações classificatórias ou de cabeçalhos de assunto.

No entanto, como bem destaca Sauperl (2002, p. 1), "a despeito da longa tradição da catalogação de assunto, ainda não se tem exatamente claro como o processo de determinação de assunto efetivamente ocorre". A denominada análise de assunto atua, assim, aos olhos do referido autor, como um processo preliminar da catalogação de assunto, que lançará as bases para que se possa, posteriormente, realizar a tradução em uma linguagem do sistema de classificação (para fins de estabelecimento de uma notação) ou de um vocabulário controlado (para fins do estabelecimento de um cabeçalho de assunto), processo que denomina sumarização (Raju \& Raju, 2006, p. 14) (4).

\section{Indexação}

Trazendo-se a discussão para o domínio da informação especializada, tem-se a literatura sobre os aspectos conceituais da indexação que, segundo autores como Neet (1989), guarda similitude com a catalogação de assunto. Essa abordagem se pauta notadamente em uma concepção de biblioteca que, distanciandose do conceito de repositório documental, mais se aproxima da função de apoio à pesquisa, como ocorre em bibliotecas especializadas e centros de documentação, cujo objetivo consiste em "adquirir, registrar, controlar, elaborar e transmitir a informação relativamente às de- mandas dos usuários e aos objetivos institucionais" (Caffo, 1988, p. 11).

Nesse contexto, destaca-se o fato de a indexação constituir uma atividade vital para a sobrevivência do sistema, ainda que não seja notada como tal, na medida em que "usuários de bibliotecas esperam dispor de ferramentas de pesquisa que lhes permitam recuperar documentos específicos sobre um determinado assunto" enquanto pesquisadores dependem da existência de índices de periódicos, ou de coleções de documentos de diferentes ordens para produzir literatura científica (Booth, 2001, p. 2).

Neet $(1989$, p. 7) destaca que o objetivo precípuo da indexação, nessas instituições, consiste em "facilitar a pesquisa de documentos ou de informações contidas em documentos". Essa dupla dimensão - documento / informação conduz aos questionamentos propostos por Batley (2005, p. 23-24): no que consiste o conteúdo do documento e a que tipo de demandas informacionais esse documento se presta. Nesse sentido, e identificando um outro binômio documento / usuário - afirma que "o classificador deve possuir um bom nível de conhecimento do assunto assim como uma clara compreensão das necessidades dos usuários".

Essa dupla e articulada dimensão documento/usuário é também defendida por Bonura (1994, p.ix), ao citar o fato de um autor norteamericano haver assinalado, no caso de livros, que "a presença de um índice significa que o autor e o editor respeitam o livro e o leitor, como consequência, irá respeitá-lo. Mutatis mutandis, pode-se dizer que a atividade de indexação significa que houve um respeito institucional pelo documento que, consequentemente, será valorizado pelo usuário.

Fidel (2000) é quem, no âmbito específico da indexação, manifesta uma preocupação mais efetiva com a dimensão de uso, por meio daquilo que denomina perspectiva centrada no usuário (aspecto que já havia sido anteriormente abordado, na década anterior, por autores como Hjorland e Albrechtsen). Nesse sentido, a autora destaca que a preocupação central estaria não em supostamente ensinar o usuário a se adaptar a um dado sistema de informação mas, sim, em identificar quais as expectativas do usuário acerca da estrutura do sistema de informação de modo a efetivamente ir ao encontro de seus hábitos de busca.

Desse modo, e considerando que é por meio de um "conjunto de procedimentos (manuais ou automatizados) para a organização e a representação do conteúdo dos documentos" que se torna possível "a recuperação dos documentos 
relevantes para uma busca de informação sobre um determinado assunto" (Caffo, 1988, p. 22), torna-se importante que os sistemas de informação estejam estruturados "de acordo com as necessidades dos usuários e não segundo regras universais" na medida em que diferentes grupos de usuários requerem distintos tipos de sistemas de informação. Assim, "quanto mais um sistema busca adequar-se às necessidades e ao comportamento de do usuário, mais amigável será o uso assim como a recuperação da informação" (Fidel, 2000, p. 79-80).

Se, por um lado, o segundo questionamento proposto por Batley (2005) encontra-se relativamente sedimentado no âmbito das pesquisas em indexação, notadamente pela incorporação de aportes da psicologia cognitiva e dos estudos de comunidade, a primeira questão, de natureza mais central na área, ainda se encontra relativamente envolta por uma névoa de incerteza: no que consiste, efetivamente, o conteúdo do documento e, indo além, como identificá-lo para uma posterior representação? Essa complementaridade da dimensão temática (ou de análise) e da dimensão de uso (ou de recuperação) são também reconhecidas por Cleveland \& Cleveland (1990, p. 16) ao afirmarem que "índices e resumos não farão qualquer sentido se não se prestarem à busca informacional.l" Essa afirmação se corrobora quando o autor alerta que a inexistência de tais produtos de T.T.I. leva o usuário de volta ao ponto de partida: o exame dos documentos um a um".

O conteúdo do documento para fins de indexação, denominado por Caffo (1988, p. 22) como "conteúdo semântico do documento" constitui, aos olhos da autora, o objeto de uma forma específica de acesso à informação, pressupondo, para tanto, uma fase de análise conceitual seguida da tradução do resultado dessa análise em uma linguagem de indexação. Para a autora, inerente ao o processo de indexação estão "a análise do documento para identificar seu conteúdo semântico bem como a tradução desse conteúdo em uma determinada linguagem documental" (Caffo, 1988, p. 22).

Esse aspecto é reiterado por Sauperl (2002, p. 7) ao afirmar que aquilo que denomina de análise de assunto de um documento inicia-se por uma operação de análise conceitual, visando a "determinar o conteúdo intelectual do documento", seguida da operação de "tradução do resultado da análise conceitual para a estrutura de uma lista de cabeçalhos de assunto ou de um sistema de classificação" adotados em um dado sistema de informação.
A denominada "análise conceitual" encontra-se voltada, como destaca Caffo (1988, p. 23) para um processo de identificação daquilo que a autora também denomina "conteúdo informacional" do documento, na medida em que esse processo constitui requisito lógico para que se possa desenvolver a representação desse conteúdo por meio de códigos de uma linguagem documental.

No entanto, destaca-se a efetiva complexidade da análise conceitual na medida em que estará permeada por três parâmetros de análise: um primeiro, no qual o documento é analisado em si mesmo, relativamente a seu próprio aboutness (Beghtol, 1986), um segundo, em que o conteúdo informativo do documento é identificado comparativamente ao contexto da unidade de informação em que se insere (tipo de coleção, tipo de uso, características da biblioteca, etc.), e um terceiro, de caráter mais técnico, ligado à política de indexação do sistema, notadamente em aspectos de exaustividade e de especificidade, que terão impactos diretos na recuperação da informação (Caffo, 1988, p. 23).

Tem-se, aqui, um aspecto diretamente ligado à consistência, elemento-chave na qualidade da indexação, de tal forma que "se um mesmo documento é indexado de forma completamente diferente por distintos indexadores ou mesmo pelo mesmo indexador, ao longo do tempo, significa de que efetivamente alguma coisa está errada" (Fungmann, 2000, p. 17).

A tripla dimensão (aboutness, contexto institucional e política de indexação) destacada por Caffo (1988) encontra reflexo nas preocupações de O'Connor (1996, p. 41), que ressalta com muita propriedade a dimensão - e as consequências - do caráter mediador do T.T.I. ao alertar que "devemos pensar na diferença entre aquilo que um autor tem em mente - aqui denominado texto - e aquilo que efetivamente chega às mãos do usuário - aqui chamado documento". Indo além o autor destaca que "tais ações podem significar que o item que efetivamente chega às mãos do usuário não é uma reprodução perfeita do conceito original do autor", mas que é a partir do documento que "ações se desenvolvem, decisões são tomadas e o usuário obtém o que busca".

Relativamente aos impactos na recuperação da informação, Fungmann (2000, p. 15) refere-se ao famoso binômio precisão $X$ revocação, defendendo que, em verdade, não são medidas opostas, mas complementares. O autor afirma que, juntamente com uma suposta oposição e situação de conflito entre a recuperação em texto integral e os processos de classificação e 
de indexação, a igualmente suposta "inversa relação entre precisão e revocação" integra uma concepção demasiado positivista na Ciência da Informação, o que tem oferecido obstáculo para o avanço teórico da pesquisa sobre análise de assunto.

Assim, advoga que a fidelidade representacional controla a precisão ao passo que a previsibilidade representacional controla a revocação de tal forma que a qualidade da recuperação dependerá crucialmente entre o grau de fidelidade e de previsibilidade representacional obtidas. Se ambas forem satisfatórias, ter-se-á igualmente um quadro de precisão e de revocação igualmente adequadas.

Referindo-se à literatura especializada, Sauperl $(2002$, p. 2,5$)$ alerta para a falta de abordagem do processo cognitivo que subjaz à identificação de assuntos de um documento. Nesse sentido, destaca o fato de os manuais tenderem a focalizar a construção de cabeçalhos de assunto ou de notações classificatórias, mas não especificamente a identificação de assuntos nos documentos. Para tanto, ressalta que o máximo a que se chega, em tais manuais, é a proposição de etapas de trabalho ou mesmo das partes de um documento que devem ser consultadas para fins de identificação temática, mas deixando ainda inexplicados e à mercê da intuição de cada indexador o processo de seleção de conceitos.

Observa-se, destarte, que em que pesem todos os avanços da concepção de indexação, notadamente no que tange ao desenvolvimento de parâmetros para elaboração e utilização de linguagens documentais, a questão procedimental relativamente à identificação e seleção de conceitos ainda aparece de maneira superficial e por vezes ingênua, no mais das vezes em concepções um tanto prescritivas sem que se discutam as variáveis lógicas e linguísticas subjacentes, como se pode observar na seguinte afirmação de Cleveland \& Cleveland (1990, p. 136):

Como em qualquer processo de indexação de assunto, o indexador começa com o reconhecimento das próprias palavras do texto, "escaneando" cada sentença e grifando as palavras-chave utilizadas pelo autor. $\mathrm{O}$ indexador, então, avalia as referidas palavras face à estrutura geral do parágrafo de modo a determinar os assuntos que estão sendo discutidos. Certamente, nem toda palavra grifada em um parágrafo constitui assunto significativo. Muitas palavras são de menor importância e não teriam utilizadas em um índice. Que tópico ou tópicos importantes são discutidos no parágrafo? Que palavras são simplesmente modificadores e não efetivamente indicadores de assunto? Por exemplo, em os mosquitos atacaram com a ferocidade de um tigre, apenas mosquitos são um indicador de assunto.

\section{Análise documental}

Se, por um lado observaram-se, nos Estados Unidos (final do século XIX e início do século $X X$ ) e na Inglaterra (metade do século $X X$ ), respectivamente, nos estudos voltados para a busca de metodologias para o desenvolvimento de produtos e de instrumentos de T.T.I., a partir do final da década de 60 e início da década de 70 verificou-se, na França, uma preocupação com o desenvolvimento de referenciais teóricometodológicos para o processo de TTI propriamente dito, vale dizer, os procedimentos envolvidos, tendo por mote o fato de, até então, tais procedimentos terem sido, no mais das vezes, encarados como "operações empíricas de bom senso dos bibliotecários” (Cunha, 1989, p. 40), com critérios diversificados e de natureza subjetiva, carecendo, pois, de parâmetros que lhes conferissem alguma cientificidade, por meio da explicitação dos procedimentos ou mecanismos envolvidos.

Desse modo, foi notadamente a partir dos trabaIhos de Jean-Claude Gardin (1966, a, b; 1967 ; $1970 ; 1973 ; 1974 ; 1981)$ e de Coyaud (1966) que se desenvolveram os estudos de forte matriz linguística da então denominada análise documental (AD) que, como ressalta Serres (s.d.), "visa a representar o conteúdo intelectual do documento, a fim de facilitar a consulta ou a posterior recuperação". Para o referido autor, a $\mathrm{AD}$ possui a natureza de uma operação intelectual "que conduz, por um lado, ao resumo do documento e, por outro, à indexação do mesmo, revelando seus conceitos-chave de conteúdo". Essa concepção é reiterada por Chaumier (1982, 1982, p. 27), ao afirmar que "a análise documental abrange dois tipos de tratamentos diferentes: a condensação, que se vale de uma redução do texto para fins de difusão da informação, e a indexação, que se vale da extração de conceitos para servir de apoio à recuperação.

A abordagem da $A D$, de orientação predominantemente francesa e com nítidos reflexos nas tradições brasileira (5), notadamente a partir dos trabalhos de Smit (1974, 1978), e espanhola (6), a partir dos trabalhos de Izquierdo Arroyo e Sagredo Fernández (1983) e de García Gutiérrez (1984), centra seu foco no processo de TTI em si, vale dizer, na explicitação dos procedimentos voltados para a identificação e seleção de conceitos para posterior representação e geração de produtos (7). 
Em termos conceituais, Fox (2005, p. 22) parte da concepção geral de análise enquanto "distinção e decomposição das partes de um todo" que, em um universo informacional, realiza-se por meio de uma operação de "reconhecimento e de estudo de um documento". Nesse âmbito, a autora, na mesma linha anteriormente trilhada por Pinto Molina (1992) e por Ruiz Perez (1992), distingue análise documental de forma e análise documental de conteúdo, notadamente quanto ao seu objeto, na medida em que a primeira se dedica à identificação dos elementos objetivos do documento (relativos a sua aparência material) ao passo que a segunda constitui uma "operação intelectual do profissional, que visa a determinar o significado geral do documento e a identificar os elementos que interessam ao processo de recuperação da informação (Fox, 2005, p. 23).

Em seu Diccionario de Bibliología y ciencias afines, José Martínez de Sousa define a análise documental como um "conjunto de operações realizadas para representar o conteúdo de um documento de forma distinta da original, com o fim de facilitar a consulta ou a recuperação da informação" e explica que, em termos gerais, a $A D$ abrange, por um lado, a descrição bibliográfica e a catalogação e, por outro, a indexação e a elaboração de resumos. (Martínez de Sousa, 1989, p. 19).

Nessa concepção, merece destaque o fato de a questão procedimental vir mais à tona, uma vez que explicitamente se reconhece a existência de um conjunto de operações, aspecto que, por sua vez, pressupõe uma lógica interna, uma sequência coerente de etapas, cada qual com objetivos precípuos.

Observe-se, ainda, que o referido autor referese a conteúdo de maneira genérica, abrangendo não apenas aspectos temáticos propriamente ditos, mas, também, àqueles relativos à forma física do documento. Tal concepção encontra respaldo em Coll-Vinent \& Bernal Cruz (1990, p. 108) para quem o objetivo da $A D$ reside em "extrair os elementos informativos de um documento original a fim de expressar seu conteúdo de forma abreviada, resultando na conversão de um documento primário em documento secundário". Para os referidos autores, esses denominados elementos informativos subsidiarão tanto a descrição bibliográfica quanto as operações de condensação e de indexação.

Nessa linha de abordagem, reitera-se a idéia dos procedimentos, pois dois momentos mais claramente se apresentam: a extração de elementos informativos seguida da sua representação abreviada.
Essas dimensões de forma e de conteúdo defendidas por Martínez de Sousa (1989) como objeto da análise documental, são defendidas por Fox (2005, p. 23) como processos consecutivos, na medida em que a análise formal, por voltar-se a elementos externos (ou de localização) do documento, deve preceder a análise de conteúdo, dedicada a elementos internos.

É interessante verificar como a questão do documento parece permear toda a tradição francesa e espanhola de AD, seja, por um lado, nas discussões da Diplomática, tal como preconizado pela École des Chartes no século XIX, seja no tocante à construção do conceito de Documentação, notadamente a partir de Paul Otlet e de Suzanne Briet (8).

Adentrando mais especificamente na dimensão temática, José López Yepes, em seu Diccionário enciclopédico de Ciencias de la Documentación, refere-se à análise de conteúdo enquanto uma modalidade específica de análise documental cujo objeto consiste em "prover os dados que permitem classificar ou indexar um documento com base em seus elementos textuais e não textuais para poder extrair as noções fundamentais e categorizá-las". Para tanto, destaca a importância de uma linguagem mediadora, seja a própria linguagem natural (de onde extrair-se-iam palavras-chave) ou uma linguagem documental (de onde extrair-se-iam notações classificatórias, cabeçalhos de assunto ou termos descritores), de tal modo a permitir a recuperação desse documento em um dado conjunto documental (López Yepes, 2004, v.1, p. 51).

Nessa definição, o autor não apenas reitera a idéia de seqüência de operações - a extração de noções fundamentais do documento e a sua categorização por meio de uma linguagem como evidencia um objetivo final desse conjunto de procedimentos, qual seja: a recuperação da informação.

Como sintetiza Fox $(2005$, p. 25,28$)$, tem-se, na $A D$, um processo comunicativo em que um conjunto de operações cognitivas de natureza analítico-sintética transforma, por meio do reconhecimento e da representação do conteúdo (ou, como prefere Chaumier, 1982 , p. 27 , do reconhecimento e da classificação de conteúdos), o documento original em outro mais exequível, fornecendo especial apoio à pesquisa científica. Tem-se, assim, como resultado, a produção de um novo documento, denominado por Fox (2005, p. 25) "documento secundário" ou, como prefere Kobashi (1994), "informação documentária" que, conforme a natureza da recuperação da informação almejada, reveste-se da forma de indexação (aqui compreendidas tanto as nota- 
ções classificatórias como os termos descritores) ou de resumo (Dégez, 2001, p. 21).

Neet (1981, p. 13) utiliza-se da expressão análise temática, que se evidenciaria (ou se materializaria) por meio da Indexação (seja ela sistemática - notações classificatórias - ou alfabética cabeçalhos ou descritores) ou da Condensação (cujo resultado pode dá-se por meio de resumos) ao passo que Maniez (2002, p. 152), valendo-se da mesma expressão, refere-se à atribuição de um índice, de uma etiqueta que permita recuperar um dado documento pelo seu assunto.

Chaumier (1982, p. 27) destaca, ainda, que a $A D$, "enquanto análise de conteúdo sob a ótica do tratamento da informação com fins documentais", se insere no cerne dos problemas da área pois é ela que, em última análise, "condiciona o valor do sistema documental" uma vez que do conjunto de operações de tratamento da informação utilizado na cadeia documental é que dependerão os resultados obtidos na fase de recuperação (Chaumier, 1982, p. 13). Em outras palavras, a AD, na concepção do autor, constitui "operação primordial sem a qual não é possível o efetivo uso da informação (Chaumier, 1982, p. 27), na medida em que é da expressão de um conteúdo de forma sintética e sem ambiguidades que efetivamente se pode falar em recuperação da informação. (Neet, 1981, p. 12; Fox, 2005, p. 23).

Especificando ainda mais a questão, Dégez (2001, p. 21) aponta para a natureza eminentemente seletiva da identificação do conteúdo temático do documento, na medida em que essa se encontra permeada pelo critério da relevância temática do texto e pelos interesses de recuperação da informação), aspectos inerentes aos parâmetros de pertinência precisão e coerência mencionados por Coll-Vinent \& Bernal Cruz (1990, p. 119-120).

Isso corrobora a assertiva defendida por Chaumier (1982, p. 18-19, 37-38) no sentido de que um trabalho de ordem eminentemente intelectual, voltado para o reconhecimento e a extração dos conceitos informativos precede necessariamente um outro, de natureza mais aplicada, voltado para a tradução desses conceitos em uma linguagem documental.

Nesse contexto teórico, há de se observar, portanto, que a $A D$, enquanto operação de decomposição (análise) e representação do conteúdo informacional dos documentos, pressupõe um conjunto sistemático e seqüencial de procedimentos que possam ser explicitados. Essa questão da explicitação dos procedimentos consiste o ponto fulcral da concepção de análise documental de Gardin pautada em aportes interdisciplinares (notadamente da Lingüística e da Lógica), necessitando, para tal, de um conjunto de ferramentas, denominadas linguagens documentais (Gardin et alii (1981, p. 29).

Cumpre destacar, nesse âmbito, que enquanto alguns autores, mais voltados para a escola inglesa (Foskett, 1973; Cavalcanti, 1982; Fujita, 1988; Amaro, 1991 e Lancaster; 1993, dentre outros), vêem identidade entre o tratamento temático da informação e a indexação, outros, mais ligados à escola francesa (Gardin, 1981; Ruiz Perez, 1992; Pinto Molina, 1993 e Guimarães, 2003) encaram a análise documental enquanto uma área (todo) na qual se insere a indexação propriamente dita (parte), o que se reflete na representação documentária, fase final do tratamento, em que se utilizam os instrumentos documentais (linguagens) para a geração de produtos documentais (índices, notações classificatórias, etc.).

Desse modo, tem-se que a ênfase da concepção de $A D$ reside na identificação, na descrição de etapas, para cujo desenvolvimento se utilizam de instrumentos e de onde decorre a geração de produtos.

Percebe-se, assim, na preocupação em explicitar procedimentos, inerente à concepção de $A D$, as bases teórico-metodológicas que neles subjazem, assim como as peculiaridades que os mesmos podem assumir em distintas áreas de especialidade ou tipologias documentais. E é com base em tais aspectos que se torna, então (e, ressalte-se, como consequência), possível proceder à construção e/ou à utilização dos instrumentos para a geração dos produtos. Por conseguinte, a ênfase procedimental evidencia a natureza eminentemente cognitiva da AD.

\section{Considerações finais}

De uma análise geral dessa literatura, observase que nas três concepções discutidas catalogação de assunto, indexação e análise documental - fica evidenciada a preocupação com o desenvolvimento de determinados processos (mais discutido pela análise documental), valendo-se de um conjunto de instrumentos (mais discutido na indexação) para que se possa chegar à geração de determinados produtos (mais discutido na catalogação de assunto) que, de forma defensável, viabilizem ou facilitem a recuperação da informação (aspecto comum a todos).

Na catalogação de assunto, como a tônica predominante reside na construção do catálogo em si, observa-se que a denominada análise de 
assunto é considerada como etapa preliminar e não central -para que se possa efetivamente desenvolver o objeto maior da questão, qual seja, a tradução em uma determinada linguagem. Nesse contexto, a questão do assunto emerge como algo mais simples, quase como que inerente e de pronto perceptível, no mais das vezes via sistema de classificação ou lista de cabeçalhos de assunto, em qualquer documento, ainda que a própria literatura da área afirme, paradoxalmente, que o nó górdio da questão situa-se no fato de ainda não se ter exatamente claro como o processo de determinação de assunto efetivamente ocorre.

Relativamente à indexação, dada a natureza mais especializada da informação, merece destaque a dupla dimensão de seu universo: o documento, por um lado, e o usuário (representado pela recuperação da informação) por outro. Nesse âmbito, a questão da análise assume uma dimensão significativamente mais específica que a da catalogação de assunto, de tal ordem que a análise propriamente dita deixa de lado a dimensão fria do assunto do documento para ir ao encontro de algo mais complexo: a dimensão conceitual do mesmo, em cujo âmbito vêm à tona aspectos como o aboutness, a informatividade (aqui se inserindo os aspectos ligados à perspectiva centrada no usuário) e, ainda, a questão conceitual no âmbito da unidade de informação em que se insere (aqui incluindo-se aspectos atinentes à política de indexação).

$\mathrm{Na}$ análise documental, por sua vez, a questão procedimental fica mais claramente evidenciada, inclusive pela nítida assunção de um espectro teórico-metodológico interdisciplinar (Linguística, Terminologia, Lógica, Psicologia Cognitiva, etc.) subjacente à delimitação e ao desenvolvimento dos procedimentos. Desse modo, a busca pela explicitação de procedimentos a partir de critérios cientificamente defensáveis passa a ser o cerne da questão, de tal forma que a análise deixa de apenas um primeiro e nebuloso estágio do T.T.I. para, efetivamente, constituirse no seu cerne, elemento condicionador do valor de todo o sistema informativo.

Por fim, destaca-se o fato de que as três linhas teóricas até então analisadas apresentam efetiva complementaridade (inclusive histórica) e, em virtude de seus distintos objetos, revelam denominações distintas para fenômenos semeIhantes, aspecto que deve ser cuidadosamente observado pelos pesquisadores, inclusive como forma de melhor sedimentar a terminologia especializada da área.

\section{Notas}

(1) O presente trabalho encontra fulcro na investigação pós-doutoral "A construção epistemológica da análise documental no contexto do Tratamento Temático da Informação: um estudo comparativo entre as realidades acadêmicas do Brasil e da Espanha" (financiada pela Fundação de Amparo à pesquisa do Estado de São Paulo - FAPESP) desenvolvido na Universidad Carlos III de Madrid, sob a supervisão do Prof. Dr. José Antonio Moreiro González, no $2^{\circ}$. Semestre de 2008. Nesse contexto, resgatam-se, criticam-se, atualizam-se e aprofundam-se aspectos anteriormente tratados (Guimarães, 2008).

(2) Acredita-se que a informação integre um movimento helicoidal e não circular ou cíclico, uma vez que a informação produzida pelo sistema nunca será igual àquela que nele ingressou originalmente.

(3) Veja-se, em Guimarães (2003) uma abordagem histórica mais detalhada do desenvolvimento do T.T.I.

(4) Chaumier (1982, p. 18-20) destaca que as listas de cabeçalho de assunto encontram seus primórdios na List of Subject Headings for use in the dictionary catalog - ALA, 1895; List of Subject Headings - LC, 1911 e CDU, 1905 ao passo que os tesauros aparecem como um novo tipo de instrumento de indexação de documentos, utilizado pela primeira vez, segundo Vickery, por Helen Browson, em 1957, na Conferência de Dorking sobre classificação, registrando-se o desenvolvimento do primeiro tesauro para fins documentais por Dupont de Nemours em 1959, nos EUA.

(5) $\mathrm{Na}$ tradição brasileira de investigação em $A D$, notadamente liderada pelo Grupo TEMMA, vejamse, dentre outros: Amaro (1991); Boccato \& Fujita (2006); Cerávolo \& Tálamo (2000); Cintra (1983, 1987); Cintra et al. (1994, 1996, 2005); Cunha (1987, 1989 a,b, 1990); Fujita (2004, 2005); Fujita, Nardi \& Fagundes (2003); Fujita, Nardi \& Santos (1998); Guimarães (1994, 2003, 2004 a,b, 2008); Guimarães \& Liberatore (2004); Guimarães \& Moraes (2006); Guimarães, Nascimento \& Moraes (2005); Kobashi (1989 a, b, 1994, 1997); Kobashi \& Lara (1996); Lara (1993 a, b, c, 1997, 2001, 2004, 2006); Lara \& Cioffi (1989); Lara et al. (1993); Moraes, Guimarães \& Guarido (2007); Smit (1974, 1978, 1987, 1996); Smit \& Barreto (2002); Smit \& Guimarães (1999) Smit \& Kobashi (2003); Tálamo (1987, 1997); Tálamo \& Lara, M.L.G. (2006); Tálamo, Lara \& Kobashi, N.Y. (1992); Tálamo \& Lenzi (2006) e Tálamo et al. (1992).

(6) $\mathrm{Na}$ tradição espanhola de investigação em $A D$ vejam-se, dentre outros: Agustín Lacruz (1996, 2006); Esteban Navarro (1995 a, b, 1996); Extremeño Placer. (2003); García Gutiérrez (1984, 1989, 1990 a, b, 1992; 1993; 1998); García Marco (1996, 1997a, b); García Gutiérrez (1984, 1989, 1990 a,b, 1992, 1993 e 1998) García Marco \& Agustín Lacruz (1999); Gil Urdiciain (1996, 
2004); Izquierdo Alonso (1999, 2000); Izquierdo Arroyo (1990, 1993, 1995); Izquierdo Arroyo \& Sagredo Fernández (1983), Marzal GarcíaQuismondo \& Moreiro González (2004); Moreiro González, J.A. (1993, 1994, 1996, 2001, 2004); Moreiro González \& Marzal García-Quismondo (2001, 2004); Moreiro González \& Robledano Arillo, J. (2003); Moreiro González, J.A. et al. (2006); Pinto Molina, M. (1992, 1993, 1994, 2001); Pinto Molina \& Gálvez, C. (1996); Rodríguez Bravo (2005); Ruiz Perez (1992); San Segundo (1996) e Valle Gastaminza (1994, 1995, 2005).

(7) Veja-se, para tanto, Silva \& Guimarães (2008).

(8) Veja-se, em Rivier (1992), uma consistente análise da trajetória das linguagens documentais, notadamente no século $X X$.

\section{Referências}

Agustín Lacruz, M. C. (1996). Lingüística documental y lenguajes documentales. Zaragoza: Proyecto Scire; Kronos, 1996.

Agustín Lacruz, M. C. (2006). Análisis documental de contenido del retrato pictórico: propuesta epistemológica y metodológica aplicada a la obra de Francisco de Goya. Cartagena: Ayuntamiento. Concejalía de Cultura; 3000 Informática, 2006.

Amaro, R. K. O. F. (1991). Contribuição da análise do discurso para a análise documentária: o caso da documentação jornalística. São Paulo: Universidade de São Paulo, 1991. Dissertação de mestrado.

Barité, M. (1998). Referenciales teóricos vigentes en el área de tratamiento temático de la información y su expresión metodológica. Porto Alegre: ABEBD, 1998.

Barité, M. (2001). Organización del conocimiento: un nuevo marco teórico-conceptual en Bibliotecología y Documentación. // Carrara, K. (org.). Educação, universidade e pesquisa. Marília: Unesp-Marília-Publicações; São Paulo: FAPESP, 2001. 35-60.

Batley, S. (2005). Classification in theory and practice. Oxford: Chandos, 2005.

Beghtol, C. (1986). Bibliographic classification theory and text linguistics: aboutness analysis, intertextuality and the congitive act of classifying documents. // Journal of Documentation. 42:2 (1986) 84-113.

Boccato, V. R. C.; Fujita, M. S. L. (2006). Discutindo a análise documental de fotografias: uma síntese bibliográfica. // Cadernos de Biblioteconomia, Arquivística e Documentação, 1, (2006) 1-18.

Bonura, L. S. (1994). The art of indexing. New York: John Willey \& Sons, 1994.

Booth, P. F. (2001). Indexing: the manual of good practice. München: K. G. Saur, 2001.

Caffo, R. (1988). Analisi e indicizzazione dei documenti. Milano: Ed. Bibliografica, 1988.

Cavalcanti, C. R. (1982). Indexação. // Machado, U. D. (ed.). Estudos avançados em Biblioteconomia e Ciência da Informação. Brasília: ABDF, 1982. 211-233.

Cerávolo, S. M.; Tálamo, M. F. G. M. (2000). Tratamento e organização de informações documentárias em museus. // Revista do Museu de Arqueologia e Etnologia da USP, 1:10 (2000) 241-253.

Cintra, A. M. M. (1983). Elementos de lingüística para estudos de indexação. // Ciência da Informação, 12:1 (1983) 5-22.
Cintra, A. M. M. (1987). Estratégias de leitura em documentação. // SMIT, J. W. (org.) Análise documentária: a análise da síntese. Brasília: IBICT, 1987. 29-37.

Cintra, A. M. M.; et al. (1994). Do termo ao descritor: estudo exploratório. // Revista Comunicações e Artes, São Paulo. $17: 28$ (1994) 75-82.

Cintra, A. M. M.; et al. (1996). Linguagens documentárias e terminología. // ALVES, I. M. (org.). A constituição da normalização terminológica no Brasil. Cadernos de Terminologia da USP, 1 (1996) 17-22.

Cintra, A. M. M.; et al. (2005) Para entender as linguagens documentárias. 2. ed. São Paulo: Polis, 2005.

Cleveland, D. B.; Cleveland, A. D. (1990). Introduction to indexing and abstracting. Englewood: Libraries Unlimited, 1990.

Coates, E. J. (1988). Subject catalogues: headings and structure. London: The Library Association, 1988.

Coll-Vienent, R.; Bernal Cruz, F. J. (1990). Curso de documentación. Madrid: Sossat, 1990.

Coyaud, M. (1966). Introduction à l'étude des langages documentaires. Paris: Klinsieck, 1966.

Cubillo, J. (1999). Cambio y continuidad en las organizaciones. Santiago (Chile): CEPAL/CLADES, 1999.

Cunha, I. M. R. F. (1987). Análise documentária. // Smit, J. W. (Coord.). Análise documentária: a análise da síntese. Brasília: IBICT, 19879.

Cunha, I. M. R. F. (1989a). Contribuição para a formulação de um quadro conceitual em análise documental. // Cunha, I. M. R. F. Análise documentária: considerações teóricas e experimentações. São Paulo: FEBAB, 1989. 15-30.

Cunha, I. M. R. F. (1989b). "O falcão maltês": a lógica em análise documentária. // Revista de Biblioteconomia de Brasília. 17:1 (jan. /jun. 1989) 51-61.

Cunha, I. M. R. F. (1990). Do mito à análise documentária. São Paulo: EDUSP, 1990.

Chaumier, J. (1982). Analyse et langages documentaires: Le traitement linguistique de l'information documentaire. Paris: Entreprise Moderne d'Edition, 1982.

Dégez, D.; Méllinet, D. (2001). Thésaurusglossaire des langages documentairtes: un outil de contrôle sémantique. Paris: ADBS, 2001.

Dias, E. J. W. (2001). Contexto digital e tratamento da informação. // DataGramaZero, 2:5 (2001). http://www. dgzero. org/out01/art_01. htm.

Esteban Navarro, M. A. (1995a). Aplicaciones de la Terminología para la docencia de la gestión de los lenguajes documentales. // Garcia Marco, F. J. (ed.). Organización del conocimiento en sistemas de información y documentación. Zaragoza: Prensas Universitarias, 1995. 205-212.

Esteban Navarro, M. A. (1995b). Los lenguajes documentales ante el paso de la organización de la realidad y el saber a la organización del conocimiento. // Scire: Representación y Organización del Conocimiento. 1:2 (1995) 43-72.

Esteban Navarro, M. A. (1996). El marco disciplinar de los lenguajes documentales: la Organización del Conocimiento y las ciencias sociales. // Scire, 2:2 (1996) 93107.

Extremeño Placer, A. I. (2003). Las ciencias cognitivas en el contexto enseñanza-aprendizaje del análisis documental de contenido. // Información, Cultura y Sociedad. 7 (2003) 117-126.

Fidel, R. (2000). The user-centered approach: how we got there. // Wheeler, W. J. (ed.). Saving the user's time through subject access innovation. Champaign, III.: The Board of Trustees of The University of Illinois, 2000. 
Fiuza, M. M. (1985). O ensino de catalogação de assunto. // Revista da Escola de Biblioteconomia da UFMG. 14:2 (1985) 257-269.

Foskett, A. C. (1973). A abordagem temática da informação. São Paulo: Polígono; Brasília: Ed. UnB, 1973.

Fox, V. (2005). Análisis documental de contenido: principios y prácticas. Buenos Aires: Alfagrama, 2005.

Fujita, M. S. L. (2004). A leitura documentária na perspectiva de suas variáveis: leitor-texto-contexto. // Datagramazero. 5:4 (2004) http://dgz. org. br/ago04/F_I_art. htm.

Fujita, M. S. L. (2005). Abordaje cognitivo de la lectura documentaria en la formación inicial del indexador: uso del protocolo verbal en la investigación de estrategias de enseñanza. // Scire. 11: 2 (2005) 1-26.

Fujita, M. S. L.; Nardi, M. I. A.; Fagundes, S. A. (2003) Observing documentary reading by verbal protocol. // Information Research, 8:4 (2003). http://informationr. net/ir/8-4/paper155. html

Fujita, M. S. L.; Nardi, M. I. A.; Santos, S. (1998). Leitura em análise documental. // Transinformação. 10:3 (1998) 1331.

Fungmann, R. (2000). Obstacles to progress in mechanized subject access and the necessity of a paradigm change. // Wheeler, W. J. (ed.) Saving the user's time through subject access innovation: papers in honor of Pauline Atherton Cochrane. Champaign, III: The Board of Trustees of The Univerasity of Illinois, 2000. 7-45.

García Gutiérrez, A. L. (1984). Lingüística documental. Barcelona: Mitre, D. L. 1984.

García Gutiérrez, A. L. (1989). Los lenguajes documentales // López Yepes, J. (comp.) Fundamentos de información y documentación. Madrid: EUDEMA, 1989. 313-342.

García Gutiérrez, A. L. (1990a). Estructura lingüística de la documentación: teoría y método. Universidad de Murcia, 1990.

García Gutiérrez , A. L. (1990b). Suficiencia estructural y tipología de la omisión en análisis documental. // Documentación de las ciencias de la información. 13 (1990) 73-86.

García Gutiérrez , A. L. (1992). Análisis documental del discurso periodístico. Madrid: CTD, 1992.

García Gutiérrez , A. L. (1993). Análisis y representación del texto en documentación: apuntes para el cambio. // Procesamiento del lenguaje natural. 13 (1993) 25-28.

García Gutiérrez, A. L. (1998). Principios de lenguaje epistemográfico: la representación del conocimiento sobre patrimonio histórico andaluz. Sevilla: Instituto Andaluz del Patrimonio Histórico, 1998.

García Marco, F. J. (1996). Principios del análisis y representación del contenido. // Rubio, E. (ed.). Teoría general de la documentación: documentación médica. Zaragoza: Kronos, 1996. 135-164.

García Marco, F. J. (1997a). Análisis documental del contenido. // Revista Española de Documentacion Cientifica, 20:2 (abr. -jun. 1997) 206-206.

García Marco, F. J. (1997b). La enseñanza de los lenguajes documentales: problemas y retos. // Martínez Comeche, J. A. (coord.). Métodos didácticos en Biblioteconomía y Documentación. Madrid: Universidad Complutense, 1997. 35-51.

García Marco, F. J.; Agustín Lacruz, M. C. (1999). El análisis de contenido de las imágenes artísticas. // Informatio. 34 (1999) 106-127.

Gardin J-C. (1966a). Analyse et sélection documentaires sans les sciences humaines. // Leroy, A. Enseignement préparatoire aux techniques de la documenation automatique. Bruxelles, Euratom, 1966. 137-146.
Gardin J-C. (1966b). Eléments d'un modèle pour la description des lexiques documentaires. // Bulletin des Bibliothèques de France. 11:5 (1966) 171-182.

Gardin J-C. (1967). Recherches sur l'indexation automatique des documents scientifiques. // Revue d'informatique et de recherche opérationnelle. 6 (1967) 27-46.

Gardin, J.-C. (1970). Procédures d'analyse sémantique dans les sciences humaines. // Pouillon, J., Maranda, P. (org.) Échanges et communications: mélanges offerts à Claude Lévi-Strauss à l'ocasion de son 60ème anniversaire. [The Hague]: Mouton, 1970. 628-657.

Gardin, J. -C. (1973). Document analysis and linguistic theory. // Journal of Documentation. $29: 2$ (1973) 137168.

Gardin J-C. (1974). Analyse documentaire et théorie linguistique. // Gardin J-C. Les analyses de discours. Neuchatel: Delachaux et Niestlé, 1974. 120-168.

Gardin, J. -C.; et alii. (1981). La logique du plausible: essais d'épistemologie pratique. Paris: Ed. Maison des Sciences de l'Homme, 1981.

Gil Urdiciain, B. (1996). Manual de lenguajes documentales. Madrid: Noesis, 1996.

Gil Urdiciain, B. (2004). Niveles de análisis documental de contenido. // Documentación de las Ciencias de la Información. 17 (2004) 77-84.

Guimarães, J. A. C. (1994). Análise documentária em jurisprudência: elementos para uma metodologia de indexação de acórdãos trabalhistas brasileiros. São Paulo: Universidade de São Paulo, 1994. Tese de doutorado.

Guimarães, J. A. C. (2001). Perspectiva de ensino e pesquisa em organização do conhecimento em cursos de Biblioteconomia: uma reflexão. // Carrara, K. (org.). Educação, universidade e pesquisa. Marília: UNESP; São Paulo: FAPESP, 2001. 35-60.

Guimarães, J. A. C. (2003). A análise documentária no âmbito do tratamento da informação: elementos históricos e conceituais. // Rodrigues, J. M.; Lopes, I. L. (org.) Organização e representação do conhecimento na perspectiva da ciência da informação. Brasília: Thesaurus, 2003. 100-117.

Guimarães, J. A. C. (2004a). Elaboração de ementas de atos normativos: elementos de análise documental com subsídio teórico à técnica legislativa. // Passos, E. (org.). Informação jurídica: teoria e prática. Brasília: Thesaurus, 2004. 9-32.

Guimarães, J. A. C. (2004b). Elaboração de ementas jurisprudenciais: elementos teórico-metodológicos. Brasília: Conselho da Justiça Federal, 2004.

Guimarães, J. A. C. (2004c). Profissional da informação: desafios e perspectivas para sua formação. // Baptista, S. G.; Mueller, S. P. M. (org.). Profissional da informação: o espaço de trabalho. Brasília: Thesaurus, 2004. 87104.

Guimarães, J. A. C. (2008). A dimensão teórica do tratamento temático da informação e suas interlocuções com o universo científico da ISKO. // Revista Ibero-americana de Ciência da Informação. 1 (2008) 77-99.

Guimarães, J. A. C.; Barité, M. (1999). Guía metodológica para el acceso, el análisis y la organización de documentos jurídicos. Montevideo: Universidad de la República, 1999.

Guimarães, J. A. C.; Liberatore, G. (2004). Panorama del análisis documental de contenido en el cono sur americano. // Nogales, T.; Caridad, M. (org.). La información en la posmodernidad: la sociedad del conocimiento en España e Iberoamerica. Madrid: Centro de Estudios Ramón Arcedes, 2004. 129-141. 
Guimarães, J. A. C.; Moraes, J. B. E. (2006). Análisis documental de contenido de textos literarios narrativos: en busca del diálogo entre las concepciones de aboutness/meaning y de recorrido temático/recorrido figurativo. // Scire. 12 (2006) 71-83.

Guimarães, J. A. C.; Nascimento, L. M. B.; Moraes, J. B. E. (2005). A diplomática como perspectiva metodológica para o tratamento de conteúdo de documentos técnicos. // Valentim, M. L. P. (org.). Métodos qualitativos de pesquisa em ciência da informação. São Paulo: Polis, 2005. 135-160.

Homulos, P. (1990). Museum to libraries: a family of collecting institutions. // Art Libraries Journal. 15:1 (1990) 1113.

Izquierdo Alonso, M. (1999). Forma del contenido y función documental: el papel de la estructura en la organización y representación del conocimiento. // López Huertas, M. J. (ed.) Representación y organización del Conocimiento en sus distintas perspectivas: su influencia en la Recuperación de Información. Granada: Universidad, 1999. 47-52.

Izquierdo Alonso, M. (2000). Nuevos enfoques en el estudio del tratamiento documental de contenido desde los presupuestos de las ciencias del lenguaje. // Scire. 6:1 (2000), 143-163.

Izquierdo Arroyo, J. M. (1990). Esquemas de Lingüística Documental. Barcelona: Promociones y Publicaciones Universitarias, 1990.

Izquierdo Arroyo, J. M. (1993). De la Semiótica del Discurso a la Semiótica Documental. // Moreiro González, J. A. Aplicación de las Ciencias del Texto al Resumen documental. Madrid: Universidad Carlos III de Madrid; Boletín Oficial del Estado, 1993. 199-216.

Izquierdo Arroyo, J. M. (1995). Estructuras conceptuales para la representación documental. // García Marco, F. J. (ed.). Organización del Conocimiento en Sistemas de Información y Documentación. Zaragoza: Librería General, 1995. 27-49.

Izquierdo Arroyo, J. M.; Sagredo Fernández, F. (1983). Concepción lógico-lingüística de la Documentación. Madrid: IBERCOM - Red COMNET de la UNESCO, 1983.

Kobashi, N. Y. (1989a). Análise documentária: considerações sobre um modelo lógico-semântico. // Cunha, I. M. R. F. (coord.). Análise documentária: considerações teóricas e experimentações. São Paulo: Federação Brasileira de Associações de Bibliotecários, 1989. 45-57.

Kobashi, N. Y. (1989b). Análise documentária e tipologias discursivas. // Cunha, I. M. R. F. (coord.). Análise documentária: considerações teóricas e experimentações. São Paulo: Federação Brasileira de Associações de Bibliotecários, 1989. 31-44.

Kobashi, N. Y. (1994). A elaboração de informações documentárias: em busca de uma metodologia. São Paulo: USP, 1994. Tese de doutorado.

Kobashi, N. Y. (1997). Resumos documentários: proposta metodológica. // Revista de biblioteconomia de Brasília. 21:2 (1997) 201-210.

Kobashi, N. Y.; Lara, M. L. G. (1996). Linguagens documentárias e terminologia. // Cadernos CITRAT. 1 (1996) 17-22.

Lancaster, F. W. (1993). Indexação e resumos. Brasília: Briquet de Lemos, 1993

Lara, M. L. G. (1993a). Algumas contribuições da semiologia e da semiótica para a análise das linguagens documentárias. // Ciência da Informação. 22:3 (1993) 223226.

Lara, M. L. G. (1993b). Linguagens documentárias instrumentos de mediação e comunicação. // Revista Brasilei- ra de Biblioteconomia e Documentação. 26:1/2 (1993) 72-80.

Lara, M. L. G. (1993c). A representação documentária: em jogo a significação. São Paulo: Universidade de São Paulo, 1993. Dissertação de mestrado.

Lara, M. L. G. (1997). Representação documentária e comunicação. // Revista Comunicações e Artes. 20:32 (1997) 73-79.

Lara, M. L. G. (2001). O unicórnio (o rinoceronte, o ornitorrinco...), a análise documental e a linguagem documentária. // DataGramaZero. 2:6 (2001) 1-13.

Lara, M. L. G. (2004a). Diferenças conceituais sobre termos e definições e implicações na organização da linguagem documentária. // Ciência da Informação, 33:2 (2004) 9196.

Lara, M. L. G. (2004b). Linguagem documentária e terminologia. // Transinformação, 16:3 (2004) 231-240.

Lara, M. L. G. (2006). É possível falar em signo e semiose documentária? // Encontros Bibli. N. esp. (2006) 18-29.

Lara, M. L. G.; CIOFFI, S. (1989). Retomando um velho tema: o mito da neutralidade na análise documental. // São Paulo em Perspectiva, 3:1/2 (1989) 92-95.

Lara, M. L. G.; et al. 1993). La interface análisis documental, lingüística documental y terminologia. // Cuadernos de Adab. 1:2 (1993) 382-388.

López Yepes, J. (ed.). (2004). Diccionário enciclopédico de Ciencias de la Documentación. Madrid: Sintesis, 2004.

Maniez, J. (2002). Actualité des langages documentaires: fondements thèoriques de la recherche d'information. Paris: ADBS, 2002.

Martínez de Souza, J. (1989). Diccionario de Bibliología y ciencias afines. Madrid: Fund. Germán Sánchez Ruipérez, 1989.

Marzal García-Quismondo, M. A.; Moreiro González, J. A. (2004). El Análisis Documental de Contenido para la sociedad del conocimiento. // Caridad, M.; Nogales, T. (coord.). La información en la posmodernidad: la sociedad del conocimiento en España e Iberoamérica. Madrid: Centro de Estudios Ramón Areces, 2004. 67-80.

Moraes, J. B. E.; Guimarães, J. A. C.; Guarido, M. D. M. (2007) Análisis documental de contenido de textos narrativos: bases epistemológicas y perspectivas metodológicas. // García Marco, F. J. (Org.). Avances y perspectivas en sistemas de información y documentación en entorno digital. Zaragoza: Prensas Universitarias, 2007. 93-100.

Moreiro González, J. A. (1993). Aplicación de las ciencias de texto al resumen documental. Madrid: Universidad Carlos III de Madrid; Boletín Oficial de Estado, 1993.

Moreiro González, J. A. (1994). Documentación y Lingüística: conceptos de relación esenciales. // Ciencias de la Información. 25:4 (1994) 202-212.

Moreiro González, J. A. (1996). La técnica del resumen científico. // López Yepes, J. (comp.). Manual de Información y Documentación. Madrid: Pirámide, 1996. 373390.

Moreiro González, J. A. (2001). Significantes y significados en el análisis documental de la imagen. // Pinto Molina, M. (ed.). Catalogación de documentos: teoría y práctica. Madrid: Síntesis, 2001. 418-492.

Moreiro González, J. A. (2004). El contenido de los documentos textuales: su análisis y representación mediante el lenguaje natural. Gijón; TREA, 2004.

Moreiro González, J. A.; Marzal García-Quismondo, M. A. (2001). Modelos teóricos y elementos funcionales para el análisis de contenido documental: definición y tendencias. // Investigación Bibliotecológica. 15:31 (2001) 125-162. 
Moreiro González, J. A.; Marzal García-Quismondo, M. A. (2004). Los modelos conceptuales y metodológicos del ADC en la sociedad del conocimiento. // Caridad, M.; Nogales, T. (coord.). La información en la posmodernidad: la sociedad del conocimiento en España e Iberoamérica. Madrid: Centro de Estudios Ramón Areces, 2004. 81-94.

Moreiro González, J. A.; Robledano Arillo, J. (2003). O conteúdo da imagem. Curitiba, Ed. Universidade Federal do Paraná, 2003.

Moreiro González, J. A.; et al. (2006). Categorización de los conceptos en el análisis de contenido: su señalamiento desde la Retórica clásica hasta los Topic Maps. // Revista Investigación Bibliotecológica: archivonomía, bibliotecología e información. 20:40 (2006) 13-31.

Neet, H. E. (1988). À la recherche du mot clé: analyse documetnaire et indexation alphabétique. Génève: Les Editions I. E. S, 1988.

Neet, H. E. (1989). L'analyse documentaire: notes et documentation destinées aux étudiants de l'École de Bibliothècaires. Génève: Institut d'Études Sociales. École de Bibliotécaires, 1989.

O'Connor, B. B. (1996). Explorations in indexing and abstracting: pointing, virtue and power. Englewood: Libraries Unlimited, 1996.

Pando. D. A. (2005). Formação e demanda profissional em tratamento temático da informação no Brasil: uma análise comparativa de conteúdos programáticos universitários e de concursos públicos em Biblioteconomia. Marília: Unesp, 2005. Dissertação de mestrado.

Pinheiro, L. V. R. (1999). Campo interdisciplinar da ciência da informação: fronteiras remotas e recentes. // Pinheiro, L. V. R. . (org.) Ciência da informação, ciências sociais e interdisciplinaridade. Brasília: IBICT/DDI/DEP, 1999. 155-182.

Pinto Molina, M. (1992). El resumen documental: principios y métodos. Madrid; Salamanca: Fundación Germán Sánchez Ruiperez; Madrid: Pirámide, 1992.

Pinto Molina, M. (1993). Análisis documental: fundamentos y procedimientos. Madrid: EUDEMA, 1993.

Pinto Molina, M. (1994). Interdisciplinary approaches to the concept and practice of written text's documentary content analysis (WTDCA). // Journal of Documentation, 50:2 (Jue 1994) 111-133

Pinto Molina, M. (2001). El resumen documental: paradigmas, modelos y métodos. Madrid: Fundación Germán Sánchez Ruiperez, 2001.

Pinto Molina, M.; Galvez, C. (1996) Análisis documental de contenido: procesamiento de información. Madrid: Síntesis, 1996.

Raju, J; Raju, R. (2006). Descriptive and subject cataloguing. Oxford: Chandos, 2006

Rivier, A. (1992). Construção de linguagens de indexação. // Revista da Escola de Biblioteconomia da UFMG, 21:1 (jan. /jun, 1992). 56-99.

Rodríguez Bravo, B. (2005). El análisis documental de documentos digitales y/o multimedia. // Códice. 1:3 (2005) 9-20.

Ruiz Perez, R. (1992). El análisis documental: bases terminológicas, conceptualización y estructura operativa. Granada: Ed. Universidad de Granada, 1992

San Segundo, R. (1996). Sistemas de organización del conocimiento: la organización del conocimiento en las bibliotecas españolas. Madrid: Universidad Carlos III de Madrid, Boletín Oficial del Estado, 1996

Sánchez Luna, B. E. (2004). Catalogación por materia. // Figueroa Alcántara, H. A. \& Ramírez Velázquez, C. A.
Organización bibliográfica y documental. México D. F.: CUIB-UNAM, 2004. 83-103.

Sauperl, A. (2002). Subject determination during the catalog process. Lanham: Scarecrow, 2002.

Serres, A. (s. d.) Introduction à l'indexation: lexique de I'indexation documentaire. http://www.uhb.fr/urfist/Sup ports/Indexation/IndexationLexique. $\mathrm{htm}$.

Silva, R. R.; Guimarães, J. A. C. (2008). Complementariedades disciplinares entre la Diplomática y la Documentación a partir del proceso de análisis documental: elementos para una reflexión. // García Marco, F. J. (org.). Avances y perspectivas en sistemas de información y documentación. Zaragoza: Prensas Universitarias de Zaragoza, 2008. 147-157.

Smit, J.; Barreto. A. A. (2002). Ciência da informação: base conceitual para a formação do profissional. // Valentim, M. L. P. (org.) Formação do profissional da informação. São Paulo: Polis, 2002. 9-23.

Smit, J. W. (1974). Analise semântica e análise documentária. // Significação. 1 (1974) 168-177.

Smit, J. W. (1978). Documentação e lingüística: inter-relação e campos de pesquisa. // Revista Brasileira de Biblioteconomia e Documentação. 11:1 (1978) 33-42.

Smit, J. W. (1986). O que é documentação. São Paulo: Brasiliense, 1986.

Smit, J. W. (1987). A análise da imagem: um primeiro plano. // Smit, J. W. (coord.). Análise documentária: a análise da síntese. Brasília: IBICT, 1987. 101-113.

Smit, J. W. (1996) A representação da imagem. // Informare. 2:2 (1996) 28-36

Smit, J. W.; Guimarães, J. A. C. (1999). Análise documentária. // Lima, Y. D.; Smit, J. W. (org.). Organização de arquivos: processamento técnico. São Paulo: USP/IEB, 1999. 62-77.

Smit, J. W.; Kobashi, N. Y. (2003). Como elaborar vocabulário controlado para aplicação em arquivos. São Paulo: Arquivo do Estado; Imprensa Oficial do Estado de São Paulo, 2003.

Tálamo, M. F. G. M. (1987). A definição semântica para a elaboração de glossário. // Smit, J. W. (org.). Análise documental: a análise da síntese. Brasília: IBICT, 1987. 87-98.

Tálamo, M. F. G. M. (1997). Linguagem documentária. São Paulo: Associação Paulista de Bibliotecários, 1997.

Tálamo, M. F. G. M.; Lara, M. L. G. (2006) O campo da Lingüística Documentária. // Transinformação. 18:3 (2006) 203-211.

Tálamo, M. F. G. M.; Lara, M. L. G.; Kobashi, N. Y. (1992). A contribuição da terminologia para a elaboração de linguagens documentárias. // Ciência da Informação. 21:3 (1992) 197-200.

Tálamo, M. F. G. M.; Lenzi, L. F. (2006). Terminologia e Documentação: a relação solidária das organizações do conhecimento e da informação no domínio da inovação tecnológica. // Datagramazero, 7:4 (2006). http://www. dgz. org. br/ago06/F_I_art. htm.

Tálamo, M. F. G. M.; et al. (1992). Análise documentária: definição de sua especificidade no contexto da ECA. // Revista de Comunicações e Artes. 16:27 (1992) 31-32.

Thomas, A. R. (ed.) (1995). Classification: options and opportunities. New York: The Haworth Press, 1995.

Valle Gastaminza, F. (1993). El Análisis documental de la fotografía. // Cuadernos de Documentación Multimedia. 2 (jun. 1993) p. 43-56.

Valle Gastaminza, F. (1994). Consideraciones sobre el análisis documental de la fotografía de prensa. // Revista General de Información y Documentación. 4:2 (1994) 169-173. 
Valle Gastaminza, F. (1995). Análisis y lenguajes documentales aplicados a la documentación audiovisual. // García Marco, F. J. (ed.). Organización del conocimiento en Sistemas de Información y Documentación. Zaragoza; Prensas Universitarias, 1995. 213-218.

Valle Gastaminza, F. (2005). La fotografía como objeto desde la perspectiva del análisis documental. // Aguayo, F.; Roca, L. (coord.). Imágenes e investigación social, México: Instituto de Investigaciones José María L. Mora/CONACYT, 2005. 243-270.

Vieira, A. S. (1998). Bases para o Brasil na sociedade da informação. // Sociedade da informação. Brasília: CNPq/IBICT; São Paulo: Instituto UNIEMP, 1998.

Vogel, M. J. M. (2007). A noção de estrutura lingüística e de processo de estruturação e sua influência no conceito e na elaboração de linguagens documentárias. São Paulo: ECA-USP, 2007. Dissertação de Mestrado. 